\title{
Mutation of PIK3CA: Possible risk factor for cervical carcinogenesis in older women
}

\author{
BAOXIA CUI ${ }^{1,2^{*}}$, BIYING ZHENG ${ }^{1,3 *}$, XI ZHANG ${ }^{1,2}$, ULF STENDAHL $^{4}$, \\ SONIA ANDERSSON ${ }^{5}$ and KENG-LING WALLIN ${ }^{1}$
}

\begin{abstract}
${ }^{1}$ Department of Molecular Medicine and Surgery, Karolinska University Hospital Solna, Karolinska Institutet, Stockholm, Sweden; ${ }^{2}$ Department of Obstetrics and Gynecology, Qilu Hospital of Shandong University, Shandong; ${ }^{3}$ Department of Clinical Microbiology, Institute of Laboratory Medicine of Guangdong Medical College, Zhanjiang, Guangdong, P.R. China;

${ }^{4}$ Department of Gynecologic Oncology, Umeå University Hospital, Umeå; ${ }^{5}$ Institute for Clinical Science, Division of Obstetrics and Gynecology, Karolinska University Hospital, Huddinge, Karolinska Institutet, Stockholm, Sweden
\end{abstract}

Received April 3, 2008; Accepted June 20, 2008

DOI: 10.3892/ijo_00000164

\begin{abstract}
PIK3CA encodes the p110 $\alpha$ catalytic subunit of PI 3-kinase, which regulates signaling pathways important for neoplasia, cell proliferation and apoptosis. Somatic mutations in this gene have been detected in several solid human tumors. We investigated these mutations in cervical carcinoma and its precursors, and their association with HPV infection and patient clinical data. The mutations were analyzed using post-PCR direct genomic DNA sequencing. Samples included 9 cervical cancer cell lines, 184 invasive cervical carcinomas, and 30 cervical neoplasias. Missense mutations of PIK3CA were identified in $15 / 184(8.15 \%)$ invasive cervical carcinomas. One novel mutation G1638C (Q546H) was found. Three mutations were identified in the cervical cancer lines. No mutations were found in the precursors. The difference in mutation frequency between invasive and pre-invavasive lesions was not significant $(\mathrm{p}=0.1372)$. In relation to age and HPV, the mutation rate was significantly higher in patients $\geq 60$ years $(p=0.001)$, while the rate of HPV infection was higher in patients $\leq 60$ years $(p=0.025)$. No significant correlation with other clinicopathological data was found. The results suggest that PIK3CA
\end{abstract}

Correspondence to: Dr Keng-Ling Wallin, Department of Molecular Medicine and Surgery, Karolinska University Hospital Solna, Center of Molecular Medicine L8:02, S-17176 Stockholm, Sweden

E-mail: keng-ling.wallin@ki.se

Dr Baoxia Cui, Department of Obstetrics and Gynecology, Qilu Hospital of Shandong University, Shandong, P.R. China

E-mail: baoxiacui@hotmail.com

${ }^{*}$ Contributed equally

Key words: cervical carcinoma, PIK3CA, mutation, cervical intraepithelial neoplasia, human papillomaviruses mutations are a late event and uncommon in the progression of malignant tumors, but it appears that they facilitate carcinogenesis in older women.

\section{Introduction}

Each year, gynecological cancers account for 5.1 million new cancer cases among women worldwide, including $\sim 493,000$ cases of cervical cancer that result in 273,000 deaths annually. Thus, cervical cancer is apparently the second most common cancer affecting women worldwide. It mainly affects women in their late 30s and older, with a high incidence rate of 9.4 per 100,000 on average in countries with screening programs. In the USA, the incidence rate in women aged 50 and older is 14.6-15.4 per 100,000 (1). The etiological role of human papillomavirus (HPV) in cervical cancer has been supported by vast epidemiological evidence and experimental studies $(2,3)$. Several population-based studies of women of all age groups showed that the prevalence of high-risk HPVs is highest among women $\leq 40$ years of age, but lower among women in older age groups (40 vs. $6 \%$ in Manchester, 25 vs. $11 \%$ in Costa Rica, 20 vs. $8 \%$ in Chile) (4-6). Prevalence differed depending on the population studied (7). Therefore, it is possible that the etiology of cervical cancer among older women is caused by genetic mutations acting in synergy with a lower immune response, rather than by infection with highrisk HPV. Biologically, high-risk HPV oncoproteins E6 and E7 can abrogate the pRb and p53 tumor suppressor pathways, and cooperate to immortalize human genital keratinocytes (8).

However, cervical cancer develops in a small proportion of women who have been infected with HPVs, and it commonly arises decades after the initial HPV exposure. These facts suggest that other factors, such as genetic aberrations may contribute to malignant transformation and tumor progression.

The phosphatidylinositol 3-kinase (PI3K)-AKT signaling pathway is involved in the regulation of diverse biological processes, including cell proliferation, survival and cycle progression $(9,10)$. The abnormal activation of this pathway is frequently observed in various types of cancer, leading to aberrant cell cycle progression, altered adhesion and motility, 
Table I. Primer sequences and PCR conditions used for PIK3CA mutation screening.

\begin{tabular}{|c|c|c|c|}
\hline Exon & Sequence $\left(5^{\prime}-3^{\prime}\right)$ & Annealing temperature $\left({ }^{\circ} \mathrm{C}\right)$ & Product length $(\mathrm{bp})$ \\
\hline \multirow[t]{4}{*}{1} & F1 CTCCACGACCATCATCAGG & 50 & 278 \\
\hline & R1 AAGCCGAAGGTCACAAAGTC & & \\
\hline & F2 CATCAACTTCTTCAAGATGA & 52 & 225 \\
\hline & R2 TAAGCTTTATGGTTATTTGC & & \\
\hline \multirow[t]{2}{*}{9} & F ATCATCTGTGAATCCAGA & 52 & 205 \\
\hline & R TTAGCACTTACCTGTGAC & & \\
\hline \multirow[t]{4}{*}{20} & F1 TGACATTTGAGCAAAGACC & 50 & 236 \\
\hline & R1 GCT CAG TTT TAT CTA AGG CTA & & \\
\hline & F2 ATT GCA TAC ATT CGA AAG A & 50 & 195 \\
\hline & R2 GTGTGGAATCCAGAGTGA & & \\
\hline
\end{tabular}

inhibition of apoptosis, and induction of angiogenesis (11), indicating the importance of the PI3K pathway in carcinogenesis. It has been reported that genetic alterations involving various members along this signaling pathway may lead to its activation. One of them is the PIK3CA gene, located at $3 \mathrm{q} 26.3$, which encodes the catalytic subunit $\mathrm{p} 110 \alpha$ of class IA phosphatidylinositol 3-kinases (PI3Ks). Gene amplifications, deletions, and recently, missense mutations in the PIK3CA gene have been found in many human cancer types (12-16). Mutated $\mathrm{p} 110 \alpha$ proteins proved to be oncogenic when studied in vitro and in vivo $(17,18)$.

It has been reported that cancer types of the liver, colon, and breast, harbor the most PIK3CA mutations with average mutational frequencies of 36,26 , and $25 \%$, respectively, while those of the lung, brain, gastric tract and ovaries are associated with lower frequencies (2-9\%) (19). However, in thyroid cancer, PIK3CA gene amplification is more frequent than gene mutations, especially in papillary $(5 \%)$ and in follicular (24\%) types of cancer (20). Clinically, patients with PIK3CA mutations showed a significantly decreased survival rate, as seen with breast cancer (21).

PIK3CA gene amplification was previously investigated in cervical cancer $(22,23)$. High rates of amplification in the $P I K 3 C A$ gene have been seen in cervical tumors (23), but few studies existed on the genetic mutations of PIK3CA in cervical tumors and their precursors. In order to investigate whether PIK3CA mutation is commonly involved in the carcinogenesis of cervical cancer, and whether this mutation correlates to clinical parameters and HPV infections, we conducted an analysis of genetic alterations particularly in the PIK3CA gene in 9 cervical cancer lines, 184 cervical cancers, and 30 cases of pre-invasive neoplasia of the cervix using direct genomic DNA sequencing.

\section{Materials and methods}

Cervical cancer cell lines. Nine cervical cancer cell lines (SiHa, HeLa, C-33A, ME180, SW756, CaSki, MS751, C-4 I and HT-3) were purchased from the American Type Culture Collection (ATCC), and were cultured in growth medium recommended by the ATCC. Reagents for cell culture were purchased from Invitrogen (Lidingö, Sweden).
Tissue and clinical samples. A total of 255 cervical samples were collected from two hospitals, Umeå University Hospital and Karolinska University Hospital Huddinge, Sweden. The samples were identified through the National Cancer Registry linked to the pathological registries of their respective hospitals. Pre-invasive samples were identified through their pathological registries. Cervical cancer staging was determined according to the FIGO system. The diagnoses and samples were kept in the archives of the respective hospitals, and clinical data and samples were obtained with the approval from the local ethics boards.

Samples from 24 patients with cervical intraepithelial neoplasia (CIN), including 7 CIN1, 10 CIN2, 7 CIN3 (4 of which were carcinoma in-situ, CIS), and 94 samples of squamous cell carcinoma of the cervix were collected from Umeå. An additional 24 samples of squamous cell carcinoma, 107 of adenocarcinoma and 6 of adenocarcinoma in-situ (AIS) of the cervix were collected from Huddinge. These samples represented three cohorts $(3,24,25)$ and were all in paraffin-embedded tissue blocks. All histological diagnoses were reviewed by at least one pathologist. Twenty samples were subsequently excluded due to the inadequate quality of the paraffin sections, leaving a total of 235 samples for mutation analysis.

DNA extraction from paraffin sections. Three to four $5 \mu \mathrm{m}$ tissue sections were obtained from each paraffin-embedded tissue block as described earlier (24). Knives were replaced and an empty paraffin block was sectioned in between tissue blocks to avoid cross-contamination. Each tumor used in this study was determined to contain at least $70 \%$ tumor cells as assessed by histopathological examination. Genomic DNA was extracted using a High Pure PCR Template Preparation Kit (Roche Diagnostics GmbH, Mannheim, Germany), following the manufacturer's instructions for paraffinembedded tissue and culture cell lines.

Mutational and sequencing analysis. Genomic DNA was evaluated for the presence of PIK3CA mutations using the PCR amplification of target sequences, followed by direct sequencing. Primers were designed as in the previous study (13) (Table I). PCR was carried out in $50 \mu 1$ of reaction mixture containing 20-100 ng of genomic DNA, $0.2 \mu \mathrm{Mol} / 1$ of each primer, $200 \mu \mathrm{Mol} / 1$ deoxynucleotide triphosphates, 
1.5-2.0 mMol/1 $\mathrm{MgCl}_{2}, 1 \mathrm{X}$ Taq Gold buffer and 0.2 units of Taq Gold DNA polymerase. After an initial denaturation step at $95^{\circ} \mathrm{C}$ for $10 \mathrm{~min}, 40$ cycles of denaturation $\left(45 \mathrm{sec}\right.$ at $\left.94^{\circ} \mathrm{C}\right)$, annealing (45 sec at appropriate temperature), and extension $\left(45 \mathrm{sec}\right.$ at $72^{\circ} \mathrm{C}$ ) were performed. This was followed by a final extension step of $72^{\circ} \mathrm{C}$ for $5 \mathrm{~min}$. PCR products were run on $2 \%$ agarose gels to verify the adequacy of the PCR reaction. The PCR products were then purified using the EXOSAP-IT method (USB Europe GmbH, Staufen, Germany). Direct sequencing was performed with an ABI 3730 automated sequencer (Applied Biosystems, Foster City, CA) using the BigDye Terminator v 3.1 Cycle Sequencing Kit (Applied Biosystems, Warrington, UK) according to the manufacturer's instructions. Any samples suspected of genetic alteration were subsequently sequenced in the reverse direction using the reverse PCR primers. The positive samples were confirmed by repeated PCR and sequencing using the same primers and conditions.

$H P V$ detection and typing. In brief, the Umeå samples were treated as previously reported $(3,24)$. The samples obtained from Huddinge were treated as reported (25). DNA extracted from the CaSki cervical cancer cell line which contained the HPV 16 genome was used as a positive control.

HPV was detected by a two-step nested PCR with MY09/11 as outer primers, which generated PCR products as templates for the inner primers, $\mathrm{GP} 5^{+} / 6^{+}$. The $50 \mu \mathrm{l} \mathrm{PCR}$ reaction volume contained $1 \mathrm{X}$ AmpliTaq PCR buffer, $10 \mu \mathrm{M}$ of each primer, $2 \mathrm{mM} \mathrm{MgCl}, 0.2 \mathrm{mM}$ of each dATP, dCTP, dGTP, dTTP (Roche Diagnostics), $5 \mu \mathrm{l}$ of $2 \%$ BSA and 1.5 units of Taq DNA polymerase (Promega, Madison, WI, USA). The PCR reaction mixture was first pre-incubated at $96^{\circ} \mathrm{C}$ for $1 \mathrm{~min}$ to denature the genomic DNA. This was followed by 40 cycles of denaturation for $30 \mathrm{sec}$ at $94^{\circ} \mathrm{C}$ and annealing at $50^{\circ} \mathrm{C}$ for $\mathrm{MY} 09 / 11$ or $40^{\circ} \mathrm{C}$ for $\mathrm{GP}^{+} / 6^{+}$for $30 \mathrm{sec}$, and an extension at $72^{\circ} \mathrm{C}$ for $45 \mathrm{sec}$. A final extension step was carried out at $72^{\circ} \mathrm{C}$ for $5 \mathrm{~min}$. Positive controls included DNA extracted from the CaSki cervical cancer cell line containing the HPV 16 genome. CaSki cells were used as positive controls and DNA free water was included in each PCR run to exclude eventual risk of contamination. HPV PCR products were purified with Qiaquick PCR purification kit (Qiagen, $\mathrm{GmbH}$, Germany). Purified PCR products generated by HPV primers were typed by direct sequencing using ABI 310 (Applied Biosystems). The quality of extracted DNA samples was assessed by PCR using S14 as a control gene (primers: forward, 5'-TCGAAAGGGGAAGGAAAAGA-3' and reverse, 5'-CAGTGACATGGACAAAAGTG-3') (3).

Statistical analysis. The Chi-square test or Fisher's exact test were used to evaluate the possible association between PIK3CA mutations, HPV infections and clinicopathological characteristics. The t-test was used to compare the mean age of patients in the different groups. Kaplan-Meier analysis and the log-rank test were used to evaluate differences in survival among patient groups. $\mathrm{P}<0.05$ was defined as being statistically significant.

\section{Results}

PIK3CA mutation identified in cervical cancer lines. Recent large-scale analyses of PIK3CA mutations in different tumor types revealed that $\geq 85 \%$ of the mutations were clustered within the p85 binding domain (exon 1), the helical domain (exon 9), and the kinase domain (exon 20) (12). Thus only exons 1,9 , and 20 of the PIK3CA gene were sequenced in these specimens.

We investigated the genomic DNA of 9 cervical cancer cell lines by direct sequencing of PCR products. Among the 9 cervical cancer cell lines, 3 (33.3\%) mutations were detected. Two of the three mutations were the same and identified in exon 9 (G1633A, E545K) in CaSki and ME180, one of the most commonly reported hotspot mutations. The HPV negative cervical cancer cell line C-33A harbored the G263A (R88Q) mutation in exon 1, which has been reported in colon cancer. No mutation of exon 20 was detected in any of the 9 cervical cancer cell lines.

PIK3CA mutation in cervical cancer types and pre-invasive cervical neoplasia. To verify whether these findings can be found in clinical samples, we examined a total of 235 samples from cervical lesions, including invasive cancers and preinvasive neoplasia (CIN and CIS). Among them, 214 cervical samples (comprising of 84 samples of invasive squamous cell carcinomas, 100 of invasive adenocarcinomas and 30 of pre-invasive neoplasia) were successfully sequenced for all three exons in the PIK3CA gene. The remaining 21 samples were excluded from this study due to failure of amplification in the PCR products or because the sequences obtained were suboptimal for evaluation. Missense mutations of PIK3CA were identified in 5 of the $84(5.95 \%)$ squamous cell cancers and 10 of the $100(10 \%)$ adenocarcinomas, resulting in an overall mutation rate of $8.15 \%$ in invasive cervical cancer specimens. No mutation was detected in the 30 samples of pre-invasive neoplastic lesions, but when compared with invasive cancer the difference was not statistically significant ( $\mathrm{p}=0.1372$ ). In total, 10 of the 15 mutations found in our material have been previously reported as hotspot mutations (exon 20:H1047R; exon 9:E542K and E545K) which had also been found in other tumors. Of these 10, 73.3\% (11/15) were clustered within the helical domain (exon 9), especially the G1633A (E545K) mutation, which accounts for $46.7 \%$ of all mutations found in invasive cancer specimens. However, we found a novel mutation, G1638C (Q546H) identified in exon 9 in an adenocarcinoma (Fig. 1, Table II), which has not been reported before. Paraffin sections representing only normal cervical tissue from the same patients were also analyzed, and no mutations were detected. Thus the results of our study suggest that these PIK3CA mutations are somatic in origin rather than germline. The specific nucleotide change, the corresponding amino substitution, and the clinical data for each patient are summarized in Table II.

PIK3CA mutation and clinicopathological features in invasive cervical cancer types. Of the 184 invasive carcinomas, 104 were in stage I, 22 in stage II, 17 in stage III, and 1 was in stage IV. Forty samples were uncharacteristic in terms of their pathological stage. Regarding histological differentiation, 49 invasive carcinomas were well differentiated, 88 moderately differentiated, and 40 poorly differentiated tumors, leaving 7 samples with an ambiguous histological grade. No correlations were observed between the presence of the PIK3CA mutation and the tumor stage, histological grade, or subtype 


\section{Exon 9 sample ub26:G1624A(E542K)}

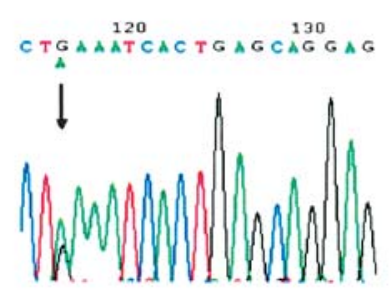

sample A15W: C1636G(Q546E)

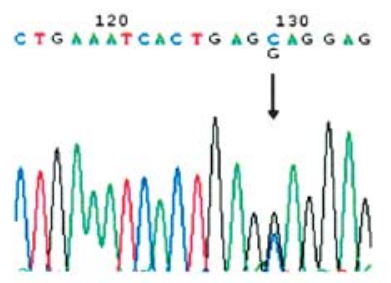

Exon 20 sample AD70:G3129A(M1043I)

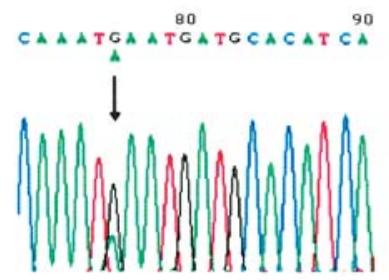

sample ub33: G1633A(E545K)

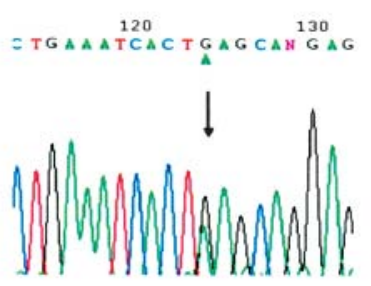

sample AD43:G1638C(Q546H)

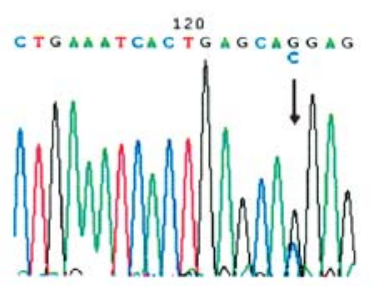

sample ub118:A3140G(H1047R)

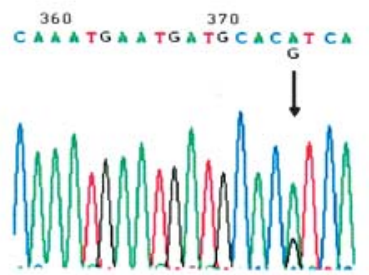

Exon 1 sample A16W: G263A(R88Q)

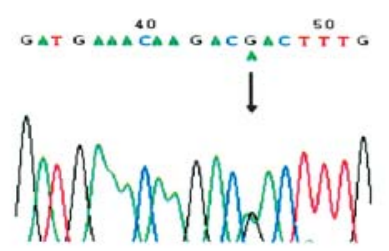

Figure 1. Mutations of PIK3CA found in cervical cancer. Arrows indicate the location of missense mutations. The altered nucleotide and the amino acid substitution are indicated above each sequencing trace.

of cervical cancers. Results of the clinicopathological features of the PIK3CA mutation in these cervical cancer types are listed in Table III.

A total of 150 patients had survival data available, among which 14 mutations were found. Their mean follow-up time was $89.03 \pm 56.28$ months (range $3-270$ ). The prognostic significance of PIK3CA was evaluated using the Kaplan-Meier analysis. The results showed no significant difference in survival time between patients who harbored the PIK3CA mutation and those who did not ( $\mathrm{p}=0.8256)$ (Fig. 2). Similarly there was no significant difference in the analysis of a subgroup of older patients ( $>60$ years). However, when correlating the PIK3CA mutation rates to the age of cancer onset in patients with invasive cervical cancer, a significant difference was found. The mean age (mean \pm SD) of patients with mutations was $61.13 \pm 12.93$ years and that of patients without was $49.03 \pm 13.9$ years $(p=0.0014)$. When stratified according to age, the mutation rate was significantly higher among patients $\geq 60$ years ( 18.87 vs. $3.88 \%, p=0.001)$ (Table III).

Correlation between HPV infection and PIK3CA mutation. HPV has an established etiological role in cervical carcinoma. We aimed to investigate whether there is any correlation between HPV infection and the PIK3CA mutation. HPV analysis was previously performed on most of our samples $(3,25)$, except for 24 samples on which HPV analysis was performed in our laboratory using the method described by Wallin et al (3). HPV data (clearly positive or negative) were available for 179 samples, but not for 5 samples. The baseline prevalence of HPV infection in our squamous cell carcinoma samples was $84.15 \%$ and in adenocarcinoma $68.37 \%$. The rate of HPV infection was found to be higher among patients $<60$ years, compared with those $\geq 60$ years 
Table II. Clinical data of cervical cancer patients with PIK3CA mutation.

\begin{tabular}{llccccccc}
\hline Patient & Age & Histotype & Stage & Differentiation & Exon & Substitution & Amino acid & HPV types \\
\hline A16W & 68 & AD & IIB & Poor & 1 & G263A & R88Q & HPV- \\
Ub26 & 67 & SQ & IIIA & Poor & 9 & G1624A & E542K & HPV16 \\
AD69 & 78 & AD & NA & Poor & 9 & G1624A & E542K & HPV16 \\
Ub49 & 46 & SQ & NA & NA & 9 & G1633A & E545K & HPV16 \\
Ub33 & 75 & SQ & IIIB & Moderate & 9 & G1633A & E545K & HPV16 \\
1 02 & 69 & SQ & NA & Poor & 9 & G1633A & E545K & HPV 33 \\
AD19 & 34 & AD & IB & Moderate & 9 & G1633A & E545K & HPV16 \\
AD39 & 64 & AD & IB & Well & 9 & G1633A & E545K & HPV16 \\
AD54 & 45 & AD & IB & Moderate & 9 & G1633A & E545K & HPV16 \\
A19G & 50 & AD & IB & Well & 9 & G1633A & E545K & HPV16 \\
A15W & 63 & AD & IIB & Moderate & 9 & C1636G & Q546E & HPV- \\
AD43 & 69 & AD & NA & Moderate & 9 & G1638C & Q546H & HPV16 \\
Ub118 & 74 & AD & IB & Moderate & 20 & A3140G & H1047R & HPV16 \\
AD70 & 70 & AD & IB & Moderate & 20 & G3129A & M1043I & HPV16 \\
Ub84 & 49 & SQ & IB & Well & 20 & G3129A & M1043I & HPV-
\end{tabular}

Tumors with PIK3CA missense mutations: 18 (AD 10, SQ 5 and 3 cell lines). Percentage of mutations: AD, 10.00 (10/100); SQ, 5.95 (5/84) and cervical cancer line 33.3 (3/9). NA, not available; AD, adenocarcinoma and SQ, squamous cell carcinoma. ${ }^{a}$ Novel mutation.

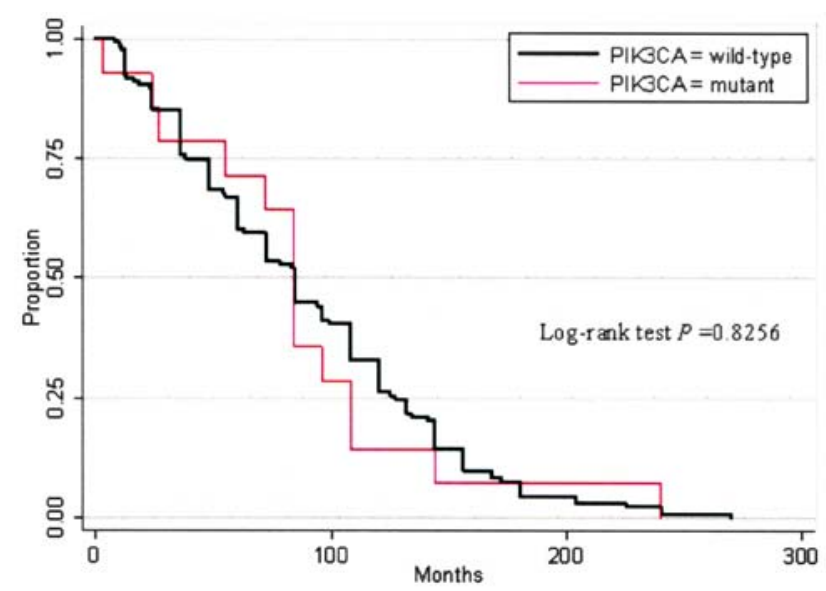

Figure 2. Kaplan-Meier survival analysis for invasive cervical patients with and without PIK3CA mutation.

( 80.62 vs. $62.75 \%, \mathrm{p}=0.012)$, in contrast to the age of patients with $P I K 3 C A$ mutations (see previously). No statistically significant association was found between HPV infection and PIK3CA mutations in cervical cancer, indicating that the PIK3CA mutation and HPV may each act independently as oncogenic factors (Table IV).

\section{Discussion}

Previous studies showed that the frequency of $P I K 3 C A$ mutation varied among different cancer types. PIK3CA mutation is more common in colon cancer (12), breast cancer (14,26-28), hepatocellular carcinomas (29), and endometrial carcinoma (30) with mutation rates $\sim 20-40 \%$. However, it is less frequent in other cancer types, such as ovarian (15), bladder (31), head and neck squamous cell cancer (16), and is rare in lung cancer $(12,32)$. The presence of PI3KCA mutations is less well documented in cervical carcinoma. The rate of mutation in cervical cancer in this study is similar to that of head and neck squamous cell cancer, in which the mutation rate is $7.4 \%$ (33). The mutation rate of $P I K 3 C A$ in this study is similar to that found in other solid tumors, though the actual mutation rate may have been underestimated since we only studied three exons.

Previous studies showed that H1047R is the most common mutation in breast, gastric and endometrial cancer $(29,30)$. Our study showed that E545K is the most common mutation among the exons examined in cervical cancer tissue $(46.7 \%$, $7 / 15)$ and the cervical cancer cell lines (2/3). Ten of the 15 mutations in invasive cervical cancer have previously been reported as hotspot mutations (i.e., H1047R, E542K and E545K). G1638C (Q546H) is a novel mutation identified in exon 9 and has not previously been described in human cancers. One mutation, Q546E, identified in a cervical cancer sample, has been reported in 1 breast cancer (28). As Q546K and Q546L have also been found in other cancers $(12,33)$, the residue glutamine ${ }^{546}$ appears to be an unstable site and may be another hotspot. Of the 18 mutations identified in cervical cancer and the cervical cancer cell lines in this study, $72.2 \%(13 / 18)$ of mutations were clustered in the helical domain (exon 9). This strongly suggests that relative to the exon 20 mutations, exon 9 mutations dominate in cervical and colorectal cancer (12), in contrast to breast and endometrial cancer, where exon 20 mutations dominate $(27,30)$.

No PIK3CA mutation was detected in any CIN and AIS lesions, while the occurrence of PIK3CA mutation is present in the early as well as in the late stage of invasive tumors. Thus, PIK3CA mutation may be associated with tumor invasiveness and the mutation may play an important role in 
Table III. Correlations between PIK3CA mutations and clinicopathological characteristics of patients with cervical cancer.

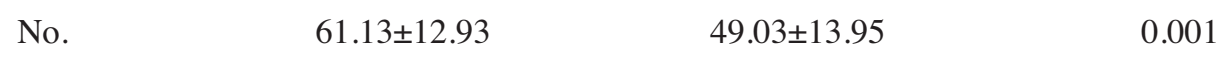

Mean age (years)

$\leq 60$

129

5

124

0.001

$>60$

53

10

43

Unknown

2

Pathological subtype

$\begin{array}{lr}\text { Squamous } & 84 \\ \text { Adeno } & 100\end{array}$

84

5

79

0.42

Clinical stage

Early (I)

100

10

90

Late (II-IV)

$7 \quad 97$
4

0.499

Unknown

Differentiation

$\begin{array}{ll}\text { Well } & 49 \\ \text { Moderate } & 88 \\ \text { Unknown } & 40\end{array}$

HPV

$\begin{array}{lrrrr}\text { Negative } & 44 & 3 & 41 & 0.676 \\ \text { Positive } & 136 & 12 & 124 & 4 \\ \text { Unknown } & 4 & & 4\end{array}$

Table IV. Correlations between HPV infection, PIK3CA, histological subtype, and patient age.

\begin{tabular}{|c|c|c|c|c|}
\hline & No. & HPV positive & HPV negative & P-value \\
\hline Mean age (years) & & 48.4 & 54.5 & 0.0146 \\
\hline$\leq 60$ & 126 & 101.0 & 25.0 & 0.043 \\
\hline$>60$ & 53 & 35.0 & 18.0 & \\
\hline Unknown & 5 & & & \\
\hline \multicolumn{5}{|c|}{ Pathological subtype } \\
\hline Squamous & 82 & 69.0 & 13.0 & 0.0141 \\
\hline Adeno & 98 & 67.0 & 31.0 & \\
\hline Unknown & 4 & & & \\
\hline \multicolumn{5}{|l|}{ PIK3CA mutation } \\
\hline Yes & 15 & 12.0 & 3.0 & 0.676 \\
\hline No & 165 & 124.0 & 41.0 & \\
\hline
\end{tabular}

the progression from severe pre-invasive to invasive cancer. It can be speculated that mutation in the PIK3CA gene may give a selective advantage to certain clones of transformed cells. Since this is not a prospective study, it cannot be ascertained as to whether these PIK3CA mutation-negative pre-invasive neoplasias will progress or regress.

Our study showed no correlation between PIK3CA mutation and HPV infection. In this study there were 5 CIN3/ CIS and 6 AIS samples with a high prevalence of HPV.
However, no PIK3CA mutation was found in any of these samples. The incidence of HPV among samples with and without PIK3CA is similar among invasive carcinomas, compared with pre-invasive neoplasia. This suggests that PIK3CA mutation rather than HPV is associated with invasion. We also found 3 samples with PIK3CA mutations among HPV-negative samples, which further suggests that these two mechanisms are independent. A few studies have reported on the PIK3CA mutation status in precancerous 
lesions of other cancer types. Hayes et al reported 2 mutations in $29(7 \%)$ specimens of uterine complex atypical hyperplasia, which is the precursor lesion of endometrial carcinoma (34), and this mutation rate is much lower than that found among endometrial carcinomas (39\%) analyzed in the study. They also concluded that PIK3CA mutation may promote invasion in endometrial tumorigenesis. Approximately $20 \%$ of our samples without any detectable HPV were negative for PIK3CA mutations, suggesting that other mechanisms of carcinogenesis may exist beyond the scope of this study.

Samuels et al analyzed sequences of all coding exons of $P I K 3 C A$ in 234 colorectal cancers and revealed mutations in a total of 74 tumors (32\%). However, they found no evidence of PIK3CA gene amplification in 96 colorectal cancers, suggesting that mutation but not amplification is a common mechanism of PI3K activation in this tumor type (12). Another study on breast cancer drew a similar conclusion (14). In contrast with these cancer types, low level amplification of PIK3CA was common in cervical cancer (23). Earlier studies showed that the $3 \mathrm{q} 26$ chromosome region was amplified by $\mathrm{CGH}$ studies (22), and proposed that PIK3CA may act as an oncogene in cervical cancer. A recent study showed high-level amplification rates $(70 \%)$ in 40 cervical neoplasia specimens using quantitative real-time PCR (23). However, few studies have evaluated the mutation status of the PIK3CA gene in cervical cancer. Our study reported a $P I K 3 C A$ incidence of mutation of $8.15 \%$ in invasive cervical cancer. Even though the mutation rate of PIK3CA was not high, we can verify that gene amplification is not the only mechanism that activates the PI3K pathway in cervical cancer.

A large-scale PIK3CA mutational analysis of 292 primary breast tumors shows a significant correlation with PIK3CA mutations to lymph node metastasis, hormone receptor and ERBB2 positivity, and an inverse relationship with functional PTEN (27). Some studies have recognized an association between PIK3CA mutations and the histological subtype $(28,35)$. The mutation rates of invasive squamous cancer and adenocarcinoma in our material were $5.95 \%$ and $10 \%$, respectively. Though the adenocarcinoma mutation rate was higher, the difference was not statistically significant. Nor did we find any correlation between PIK3CA mutations and tumor stage or histological grade. We found a significant difference between the age of patients with and without mutations. Furthermore, HPV infections are more prevalent among younger patients while PIK3CA mutations are more commonly found in older patients diagnosed with invasive cervical cancer. This has been postulated in the past, but seldom reported. This phenomenon may reflect differing mechanisms of carcinogenesis between older and younger patients with cervical cancer. PIK3CA mutation may be more of a risk factor for older women than younger women.

In conclusion, this study focuses on the rate of PIK3CA mutation in cervical cancers of the two histological types (squamous and adenocarcinomas). Concerning the cancer incidence rate in Sweden, our sample sizes are representative of the two tumor types. Cervical squamous cell carcinomas are strongly associated with high-risk HPV infections. However, HPV DNA has not been identified in the same proportion in adenocarcinoma of the cervix. Factors other than sexually-transmitted HPV are therefore potentially responsible. PIK3CA mutations have been suggested to be an oncogene in gynecological cancers. However, oncogenic HPV and PIK3CA mutations may be involved in the progression to cervical carcinomas, but may act independently of each other. In this study, PIK3CA mutations are more frequently found in the tumors of older than younger women and may therefore be an additional risk factor for older women. The lower immune response in older women may also mean that their immunosurveillance of either HPV infection or cellular transformation is less robust and therefore predisposes them to carcinogenesis. It can be assumed that the two factors may occur simultaneously and that the biological process is complicated by the variation of the human genome, the influence of genetic and environmental factors in different geographical regions, as well as by an uneven distribution of the varieties of HPV worldwide.

\section{Acknowledgments}

We are grateful to Joakim Dillner, Xiangning Zhang and Weng-Onn Lui for scientific comments and discussions. This study was supported by the Swedish Cancer Society, Stockholm County Council, the Swedish Medical Research Council, the Swedish Cancer Foundation and a grant (30400475) from the National Natural Science Foundation of P.R. China.

\section{References}

1. Saraiya M, Ahmed F, Krishnan S, Richards TB, Unger ER and Lawson HW: Cervical cancer incidence in a prevaccine era in the United States, 1998-2002. Obstet Gynecol 109: 360-370, 2007. Erratum in: Obstet Gynecol 109: 1002, 2007.

2. Munoz N, Bosch FX, de Sanjose S, Herrero R, Castellsague X, Shah KV, Snijders PJ and Meijer CJ: International Agency for Research on Cancer Multicenter Cervical Cancer Study Group. Epidemiologic classification of human papillomavirus types associated with cervical cancer. N Engl J Med 348: 518-527, 2003.

3. Wallin KL, Wiklund F, Angstrom T, Bergman F, Stendahl U, Wadell G, Hallmans G and Dillner J: Type-specific persistence of human papillomavirus DNA before the development of invasive cervical cancer. N Engl J Med 341: 1633-1638, 1999.

4. Herrero R, Castle PE, Schiffman M, Bratti MC, Hildesheim A, Morales J, Alfaro M, Sherman ME, Wacholder S, Chen S, Rodriguez AC and Burk RD: Epidemiologic profile of typespecific human papillomavirus infection and cervical neoplasia in Guanacaste, Costa Rica. J Infect Dis 191: 1796-1807, 2005.

5. Ferreccio C, Prado RB, Luzoro AV, Ampuero SL, Snijders PJ, Meijer CJ, Vaccarella SV, Jara AT, Puschel KI, Robles SC, Herrero R, Franceschi SF and Ojeda JM: Population-based prevalence and age distribution of human papillomavirus among women in Santiago, Chile. Cancer Epidemiol Biomarkers Prev 13: 2271-2276, 2004.

6.Kitchener HC, Almonte M, Wheeler P, Desai M, Gilham C, Bailey A, Sargent A and Peto J: ARTISTIC Trial Study Group: HPV testing in routine cervical screening: cross sectional data from the ARTISTIC trial. Br J Cancer 95: 56-61, 2006.

7. Franceschi S, Herrero R, Clifford GM, Snijders PJ, Arslan A, Anh PT, Bosch FX, Ferreccio C, Hieu NT, Lazcano-Ponce E, Matos E, Molano M, Qiao YL, Rajkumar R, Ronco G, de Sanjose S, Shin HR, Sukvirach S, Thomas JO, Meijer CJ and Munoz N: Variations in the age-specific curves of human papillomavirus prevalence in women worldwide. Int J Cancer 119: 2677-2684, 2006.

8. Munger K and Howley PM: Human papillomavirus immortalization and transformation functions. Virus Res 89: 213-228, 2002.

9. Coffer PJ, Jin J and Woodgett JR: Protein kinase B (c-Akt): a multifunctional mediator of phosphatidylinositol 3-kinase activation. Biochem J 335: 1-13, 1998. 
10. Cantley LC: The phosphoinositide 3-kinase pathway. Science 296: 1655-1657, 2002

11. Vivanco I and Sawyers CL: The phosphatidylinositol 3-kinase AKT pathway in human cancer. Nat Rev Cancer 2: 489-501, 2002.

12. Samuels Y, Wang Z, Bardelli A, Silliman N, Ptak J, Szabo S, Yan H, Gazdar A, Powell SM, Riggins GJ, Willson JK, Markowitz S, Kinzler KW, Vogelstein B and Velculescu VE: High frequency of mutations of the PIK3CA gene in human cancers. Science 304: 554, 2004.

13. Garcia-Rostan G, Costa AM, Pereira-Castro I, Salvatore G, Hernandez R, Hermsem MJ, Herrero A, Fusco A, Cameselle-Teijeiro J and Santoro M: Mutation of the PIK3CA gene in anaplastic thyroid cancer. Cancer Res 65: 10199-10207, 2005.

14. Wu G, Xing M, Mambo E, Huang X, Liu J, Guo Z, Chatterjee A, Goldenberg D, Gollin SM, Sukumar S, Trink B and Sidransky D: Somatic mutation and gain of copy number of PIK3CA in human breast cancer. Breast Cancer Res 7: R609-R616, 2005.

15. Levine DA, Bogomolniy F, Yee CJ, Lash A, Barakat RR, Borgen PI and Boyd J: Frequent mutation of the PIK3CA gene in ovarian and breast cancers. Clin Cancer Res 11: 2875-2878, 2005.

16. Qiu W, Schonleben F, Li X, Ho DJ, Close LG, Manolidis S, Bennett BP and Su GH: PIK3CA mutations in head and neck squamous cell carcinoma. Clin Cancer Res 12: 1441-1446, 2006.

17. Ikenoue T, Kanai F, Hikiba Y, Obata T, Tanaka Y, Imamura J, Ohta M, Jazag A, Guleng B, Tateishi K, Asaoka Y, Matsumura M, Kawabe T and Omata M: Functional analysis of PIK3CA gene mutations in human colorectal cancer. Cancer Res 65: 4562-4567, 2005.

18. Bader AG, Kang S and Vogt PK: Cancer-specific mutations in PIK3CA are oncogenic in vivo. Proc Natl Acad Sci USA 103: 1475-1479, 2006.

19. Karakas B, Bachman KE and Park BH: Mutation of the PIK3CA oncogene in human cancers. Br J Cancer 94: 455-459, 2006.

20. Wu G, Mambo E, Guo Z, Hu S, Huang X, Gollin SM, Trink B, Ladenson PW, Sidransky D and Xing M: Uncommon mutation, but common amplifications, of the PIK3CA gene in thyroid tumors. J Clin Endocrinol Metab 90: 4688-4693, 2005.

21. Li SY, Rong M, Grieu F and Iacopetta B: PIK3CA mutations in breast cancer are associated with poor outcome. Breast Cancer Res Treat 96: 91-95, 2006.

22. Ma YY, Wei SJ, Lin YC, Lung JC, Chang TC, Whang-Peng J, Liu JM, Yang DM, Yang WK and Shen CY: PIK3CA as an oncogene in cervical cancer. Oncogene 19: 2739-2744, 2000.

23. Bertelsen BI, Steine SJ, Sandvei R, Molven A and Laerum OD: Molecular analysis of the PI3K-AKT pathway in uterine cervical neoplasia: frequent PIK3CA amplification and AKT phosphorylation. Int J Cancer 118: 1877-1883, 2006.

24. Chua KL, Wiklund F, Lenner P, Angstrom T, Hallmans G, Bergman F, Sapp M, Schiller J, Wadell G, Hjerpe A and Dillner J: A prospective study on the risk of cervical intra-epithelial neoplasia among healthy subjects with serum antibodies to HPV compared with HPV DNA in cervical smears. Int J Cancer 68 54-59, 1996.
25. Andersson S, Rylander E, Larsson B, Strand A, Silfversvard C and Wilander E: The role of human papillomavirus in cervical adenocarcinoma carcinogenesis. Eur J Cancer 37: 246-250, 2001.

26. Bachman KE, Argani P, Samuels Y, Silliman N, Ptak J, Szabo S, Konishi H, Karakas B, Blair BG, Lin C, Peters BA, Velculescu VE and Park BH: The PIK3CA gene is mutated with high frequency in human breast cancers. Cancer Biol Ther 3: 772-775, 2004.

27. Saal LH, Holm K, Maurer M, Memeo L, Su T, Wang X, Yu JS, Malmstrom PO, Mansukhani M, Enoksson J, Hibshoosh H, Borg A and Parsons R: PIK3CA mutations correlate with hormone receptors, node metastasis, and ERBB2, and are mutually exclusive with PTEN loss in human breast carcinoma. Cancer Res 65: 2554-2559, 2005.

28. Campbell IG, Russell SE, Choong DY, Montgomery KG, Ciavarella ML, Hooi CS, Cristiano BE, Pearson RB and Phillips WA: Mutation of the PIK3CA gene in ovarian and breast cancer. Cancer Res 64: 7678-7681, 2004.

29. Lee JW, Soung YH, Kim SY, Lee HW, Park WS, Nam SW, Kim SH, Lee JY, Yoo NJ and Lee SH: PIK3CA gene is frequently mutated in breast carcinomas and hepatocellular carcinomas. Oncogene 24: 1477-1480, 2005.

30. Oda K, Stokoe D, Taketani Y and McCormick F: High frequency of coexistent mutations of PIK3CA and PTEN genes in endometrial carcinoma. Cancer Res 65: 10669-10673, 2005.

31. Lopez-Knowles E, Hernandez S, Malats N, Kogevinas M, Lloreta J, Carrato A, Tardon A, Serra C and Real FX: PIK3CA mutations are an early genetic alteration associated with FGFR3 mutations in superficial papillary bladder tumors. Cancer Res 66: 7401-7404, 2006.

32. Kawano O, Sasaki H, Endo K, Suzuki E, Haneda H, Yukiue H, Kobayashi Y, Yano M and Fujii Y: PIK3CA mutation status in Japanese lung cancer patients. Lung Cancer 54: 209-215, 2006.

33. Kozaki K, Imoto I, Pimkhaokham A, Hasegawa S, Tsuda H, Omura $\mathrm{K}$ and Inazawa J: PIK3CA mutation is an oncogenic aberration at advanced stages of oral squamous cell carcinoma. Cancer Sci 97: 1351-1358, 2006.

34. Hayes MP, Wang H, Espinal-Witter R, Douglas W, Solomon GJ, Baker SJ and Ellenson LH: PIK3CA and PTEN mutations in uterine endometrioid carcinoma and complex atypical hyperplasia. Clin Cancer Res 12: 5932-5935, 2006.

35. Buttitta F, Felicioni L, Barassi F, Martella C, Paolizzi D, Fresu G, Salvatore S, Cuccurullo F, Mezzetti A, Campani D and Marchetti A: PIK3CA mutation and histological type in breast carcinoma: high frequency of mutations in lobular carcinoma. J Pathol 208: 350-355, 2006 